meninges through the perineural lymphatics of the olfactory nerve which are known to be in direct communication with the subarachnoid lymph spaces.

From the first the infection in the present case was interpreted as blood-borne. The practically universal distribution of the extravasated blood, the comparative thinness of the layer, and the absence of any definite focus from which the condition appeared to spread, all seem to preclude any other explanation. Moreover, at the base of the brain the amount of extravasated blood was relatively small and nothing called attention to the points at which the lymphatic channels pass inwards or outwards. The cribriform plates and the roots of the optic nerves certainly presented no hæmorrhagic lesion. Judging by the condition of the lymphatics of the intestine in the neighbourhood of the pustules, had the organisms reached the skull by channels of this nature there would have been a local lesion and a spreading lesion centred about it. Where there had been great hæmorrhage such a lesion might well be obscured, but this could not have been the case where the lesion was at such an early stage as in the present case. No nasal discharge was noted during life. Moreover, there was clearly a generalised infection, although the bacilli were not numerous in the blood. The extreme dilatation and breaking down of the walls of the bloodvessels in the pia mater and in the intestines where bacilli were numerous may be interpreted as due to toxic canses working from without, but in the spleen, the mesentery, and the mediastinal tissues it may be, and in the tongue, the cerebrum, and the kidney it must be, regarded as due to an internal cause. A reason, although not an explana. tion, why it should have produced such extraordinary effect on the vessels of the brain may perhaps be found in the cirrhosis of the kidney - a condition which is commonly held to favour cerebral and meningeal hæmorrhage. Moreover, a few little hæmorrhages (represented by the older masses of blood and leucocytic exudation mentioned in the description of the brain) would allow some escape of bacilli into the meninges where they found a favourable nidus in which to develop. Then the external toxic effects would speedily produce further bleeding and a condition which corresponds with the extreme rapidity of the last phase of the clinical course of the case.

An additional proof at once of the intestinal nature of the primary infection and of the blood-borne character of the infection of the meninges is supplied by the discovery of fragments of columnar-celled epithelium in the blood in the meninges. These were at first regarded as accidental and due to some fault in handling of the material, but further investigation showed that this view must be abandoned. The structures were found deep in the sulci of the cerebrum in rections from the centre of blocks of tissue which had been carefully fixed and imbedded in paraffin. 'They were clearly in the blood in the sulci and must, I think, have been brought there by the blood stream. Similar structures were found in the submucous coat of the principal intestinal lesion, where they were recognised as identical with the epithelium covering the villi and lining the Lieberkühnian crypts. How they came into their position is not clear but they appear to have entered at the central necrotic area of the lesion.

Analogous observations referring to bronchial ciliated epithelium in the first case and bile-duct epithelium in the second are recorded by Foà and Lubarsch. ${ }^{25}$ The condition is very curious, as these structures have no close relationship to the blood-stream such as is seen in the well-known embolism of bone marrow and placental cells.

Summary. - In conclusion little need be said. Clinically the case was one of acute illness terminating fatally within 24 hours, the prominent features of which were headache, cerebral irritation manifesting itself in restlessness, delirium, and finally convulsions. There was also slight abdominal tenderness which might have suggested peritonitis but there was no pyrexia. The history afforded no hint as to the nature of the disease. At the post-mortem examination the case presented the features of an acute septicæmia and early peritonitis which appeared to spread from a hæmorrhagic lesion of the small intestine with ulceration and necrosis internally and signs of an infective process extending up the mesentery. The nervous phenomena were explained by the discovery of a diffuse hæmorrhagic condition of the pia-arachnoid, which microscopical

25 Foà and Lubarsch: Lubarsch's Allgemeine Pathologie, 1905, examination demonstrated to be an early meningitis due to the bacillus anthracis. The identity of the organism was proved by cultivation and inoculation experiments. The intestinal lesion was clearly the oldest and the conclusion appears fally warranted that the case was anthrax septicæmia due to intestinal infection caused most probably by the ingestion of a quantity of anthrax bacilli or spores in food.

I have to express $m y$ indebtedness to Professor $\mathbf{R}$. Stockman and Professor R. Muir for permission to publish the case, to Dr. Bell for the clinical notes, and to Dr. Chalmers and Dr. Buchanan for permission to use their reports.

Glasgow.

\section{A NOTE ON THE TECHNIQUE OF COLON-IRRIGATION IN A CASE OF APPENDICOSTOMY FOR COLITIS.}

By WILliam EWART, M.D. CantaB., F.R.C.P. Lond., SENIOR PHYSICIAN TO ST. GEORGE'S HOSPITAL AND TO THE BEIGRAVE HOSPITAL FOR CHILDREN.

As the procedure which I have used in this case has been alluded to both by Sir William Bennett ${ }^{1}$ and by Mr. C. B Keetley $^{2}$ a brief description of these beginnings in the utilisation of the appendix for therapeutic purposes may not be inopportune. 'The patient, a female, aged 44 years, now convalescent after upwards of 12 months' diarrhcea and wasting from mucous colitis, was sent to me for diagnosis and treatment by Mr. T. J. Hitchins under some suspicion of a carcinomatous affection which was suggested by the intractable nature of the complaint and by a slight tendency to hæmorrhage from the bowel. After ineffectual medical and dietetic measures appendicostomy was decided upon and was performed for me on Dec. 20 th by Sir William Bennett, as described in his lecture, ${ }^{1}$ most successfully and with the happiest results as regards complete freedom from surgical complications and from any troublesome leakage of gas or of fæces. Since that date the colitis has been treated through the appendix by myself and by my skilful house physicians, Mr. J. H. Bankes and Mr. J. Aylen, with a variety of remedies, such as extensive irrigations with saline solution, starch water, infusion of marshmallow, \&c., and injections of oil, of lime water, of varions astringents, of ipecacuanha powder in suspension together with cinnamon and charcoal, of glycothymolin, and of argyrolnone of which stopped the profuse discharge of bloodstained mucus. 'This ceased, however, a fortnight after beginning a course of a simple daily injection of two ounces of liquid paraffin into the cæcum, charcoal being administered by the mouth. Further therapentical details are unnecessary, as the main object of this communication is to describe the mode of performance of the injection and irrigation of the cæcum and colon and of the systematic irrigation of the lower part of the ileum.

1. Irrigation of the crecum and colon.-For this I used a No. 8 male indiarubber catheter, with a very pliable soft copper wire as stilette, bent upon itself at its extremity to obviate the risk of any injury to the mucous membrane. Dipped in glycerine the catheter slips in easily into the cæcum, where it is apt to coil itself if more than a few inches of its length are introduced, as was shown in a skiagram taken by Mr. F. Thornton Addyman. The largest irrigation used was of 20 pints, supplied from an irrigator under moderate pressure. The patient, placed in the dorsal decubitus, is previously provided with a good-sized rectal tube with attached outflow tube. It is convenient to insert one or two glass joints in the length of both sets of tubing. No pain or undue distension results if the way should remain clear. Should, however, any delay occur in the outflow other than the normal periodic intermissions due to peristalsis of the colon it will probably be found that the cæcum has become distended and that by turning the patient slightly towards the left the flow will be restored. A judicious use of the clipe on the supply tube and on the rectal outflow tube can be

1 The Lancet, Feb. 17th, 1906.

3 St. George's Hospital Medical Register, No. 1940 of 1900 
made to bring about, if desirable, a moderate state of distension of the entire colon. Simple injections for retention in the bowel do not require the rectal tube which should be removed after the preliminary irrigation. They are conveniently performed with the help of a large surgical syringe.

2. Injeotion and irrigation of the lower ileum.-As a ready access to the small intestine was part of the object of the operation, in case it should have been diseased, and with a thought also for the requirements of typhoid fever cases, I directed most of the injections which I myself performed into the small intestine, having previously worked out the method in the dead body with Sir William Bennett. The modus operandi is simple and has been found quite easy by my house physicians as well as by myself. The catheter is bent (not too sharply) to about $110^{\circ}$ at a point two and a half inches from its tip. It is to be introduced, not sagittally as when it is intended for use in the cæcum, but inwards and downwards as well as backwards in the direction of the nearest spot on the brim of the pelvis. The assurance that the catheter has entered the small intestine is given by the greater length introduced (maximum in this case nine inches), by the subjective sensations of the patient experienced in the hypogastrium even so far as the middle line, by the direct palpation through the abdominal wall sometimes ootained by the operator, and by the skiagram of the stilette in situ.

3. Systematic lavage of the lower ileum, such as might be suitable for ulcerative typhoid fever, is best performed with two tubes instead of the single catheter. With the valuable assistance of Mr. Aylen I have satisfied myself in this case that a therapeutic lavage of the last portion (probably a foot or $t w o$ ) of the ileum could be readily achieved after a preliminary cleansing irrigation. For this special purpose I have introduced side by side a No. 2 gum catheter and a No. 6 gum catheter; but I should prefer the indiarubber instruments if made thinner in the wall. The small catheter is passed through the valve first, in the manner which $I$ have described, to the distance desired, and the larger one is then introduced into the cæcum, where it acts as a draw-off for the fluid injected higher up. This arrangement might enable antiseptics to be used locally which it might not be desirable to expose to absorption by the mucous membrane of the entire colon. The quantity injected being noted evidence would be obtained that it had been duly recovered from the cæcum either by simple syphonage or if necessary by aspiration with the syringe. For this lavage the patient shoula assume a three-quarters right lateral decubitus to promote the descent of the injected fluid into the crecum.

Although the experience which I have detailed has been gained in a single case it will probably apply in general outline to the majority of cases. The anatomical relation of the ileo-crcal valve to the brim of the pelvis is not liable to much variation and that which exists between the valve and the entrance to the appendix is also fairly constant; it is in the direction taken by the tail of the latter that the chief individual differences are found and these would be eliminated by dividing the appendix high up. A short stump would also afford the advantage of a broader way into the bowel, although it might fail perhaps to provide for a faithful sphincter-like action.

Remarks on Appendicostomy and the Ireatment of Typhoid Fever.

The answer to the question proposed by Mr. Keetley in THE LANCET of April 14th, "Ought not typhoid fever patients to be operated on before fatal perforation and bleeding occur?" must ultimately depend upon the results which may be achieved by early surgical interference when it comes to be tried. It is clearly too late to begin any local treatment of the bowel when the patient is in extremis. These resuscitation operations are a purely surgical concern and have nothing in common with the local therapeutic method for which surgical assistance may be desired by the physician. I may be allowed to state that the anxiety with which I have been credited by Sir William Bennett ${ }^{\epsilon}$ and by Mr. Keetley ${ }^{7}$ to utilise appendicostomy for the benefit of

5 Dr. Ewart showed us two skiagrams which we were unable to reproduce. The one showed the catheter lying in the ascending colon and the other showed it in the small intestine passing across from the right-hand side of the false pelvis, across the middle line till the point was lost about the brim of the true pelvis on the lefthand side.-ED. L.

$$
\begin{aligned}
& 6 \text { The Lancet, Feb. 17th, 1906, p. } 419 . \\
& 7 \text { The LanceT, April 14th, 1906, p. } 1023 .
\end{aligned}
$$

typhoid patients is in reality little more than a return to views which I had held for years as to the necessity for a local treatment of the ulceration presumably by a surgical route, until the favourable results yielded by the "empty bowel treatment," which I described in my last published clinical lecture on the Principles of Treatment of Typhoid Fever, ${ }^{8}$ led me to hope that surgical help might be dispensed with. This apparent change of front is only as to the means It is not due to any less regard for the "empty bowel treatment" but to a more personal acquaintance with the special facilities for local treatment combined in appendicostomy with a minimum of operative risk and of after trouble. Indeed, my obligation to Sir William Bennett for having for years discouraged my appeals for modes of interference offering doubtful surgical prospects is not less than that I owe him for having finally provided me with this more hopeful method; and once more the possibilities connected with surgical access to the bowel must command my careful consideration in spite of my recent disclaimer.

Mr. Keetley in the concluding paragraph of his important and suggestive paper alludes to some possibly superior advantages of enterostomy. Without presuming to discuss the surgical merits of the two operations, and although this is a purely academical stage in their discussion, I may perhaps record my preference for the less severe one which entails little interference with the intestinal economy, and in that sense affords much better scope for local medical treatment. For I cordially agree with Mr. Keetley's sentiment that "the operative treatment of typhoid fever ought not to mean taking the disease out of the physician's domain and transferring it to the surgeon's. It is a means of facilitating treatment by the physician."

I have briefly sketched the mechanical technique adapted for the "appendicotherapy" which may soon be made avail. able for the treatment of the " typhoid segment" both when ulcerated and, perhaps better still, prophylactically prior to ulceration. Meanwhile, my therapeutic endeavour is not, either in this or in any other affection, to extend but rather to contract the surgical frontier. I still consider that the medical resources for the cure or the curtailment of the typhoid attack are by no means exhausted. But if the knife should prove to be an indispensable accessory to that achievement I should not decline its service. I also believe that Mr. Keetley's question as to the proper time for surgical interference would then be decided on grounds of public health; and that it would probably be decided in favour of a sterilisation of Eberth's bacillus in situ intestinali with a minimum of surgery and of the utmost reduction by that way of the spread of typhoid infection.

Curzon-street, W.

\section{TWO UNUSUAL CASES OF DIFFICULT LABOUR.}

BY H. T. HICKS, F.R.C.S. ENG.,

OBSTETRIC REGISTRAR AND TUTOR, GUY'S HOSPITAL; AND ASSISTANT SURGEON TO THE SAMARITAN FREE HOSPITAL.

CASE 1.-The patient, a married woman, aged 31 years, had had one full-term child, born dead after a prolonged labour which ended in a difficult forceps delivery; this was two years ago. She had now reached the full term of her second pregnancy. Labour pains began in the afternoon of March 27th. The os was only slightly dilated and the face was found presenting; the membranes ruptured about 9.30 P.M. As the face did not descend and the pelvis was contracted version was attempted by the patient's medical man about two hours after the membranes had ruptured. The face was lifted out of the brim without difficulty and the right foot was found close down beside the head. The head was said to be moveable. Traction on the leg failed to move the child and after a prolonged attempt, first at version and then at applying forceps to the head under an anæsthetic, the patient was taken to Guy's Hospital in the early hours of March 28th. On admission the pulse was 136 per minute but the general condition was fairly good. There were great swelling and bruising of the rulva and vagina. On abdominal examination the extended head conld be felt easily just above the pubes in front; it was freely moveable and Bandl's ring 